\title{
Changes of mechanical properties of hot rolled steel as a result of a reducing of rigidity of the rolling stands
}

\author{
Kurapov G. ${ }^{1}$, Lezhnev S. ${ }^{2, a}$, Orlova E. ${ }^{1}$, Volokitina I. ${ }^{1}$, Bedelova A. ${ }^{1}$, Panin E. ${ }^{2}$ \\ ${ }^{1}$ Kazakh national technical University after K.I. Satpaev, Almaty, Kazakhstan \\ ${ }^{2}$ Karaganda state industrial University, Temirtau, Kazakhstan \\ asergey_legnev@mail.ru
}

Keywords: hot rolled steel, mechanical properties, stiffness.

\begin{abstract}
This article is devoted of changes of mechanical properties of hot rolled steel as a result of a reducing of rigidity of the rolling stands. From the analysis of studies of hot rolled steel statistically it is shown that as a result of reconstruction the change of stiffness of working stands of rolling mill has led to an increase in the tensile strength and yield strength and lower limit plasticity laminated metal. Therefore, the change in the stiffness of deforming device and tool causes a change in the properties.
\end{abstract}

\section{Introduction}

The development of ideas about the mechanism of plasticity in the last 50 years suggest that the basis of the plasticity of metals are flowing in them physic-chemical transformations, which make the possibility of changing the body shape without fracture. The presence of physical and chemical transformations during plastic deformation of metals are observed by all researchers as a change in the structure, mechanical properties, plasticity, appearance of new phases, and so on [1-4]. However, in the research literature on the basis of plasticity are moving lattice defects (dislocations, disclinations), while physic-chemical transformations are treated as a secondary, but not primary, not defining the nature of plasticity.

Based on the analysis of our own experiments and analysis of numerous publications we have built the model of the flow of plastic deformation in crystalline structures and in particular in metals [5-7] based on the experimental fact of physic-chemical transformations. Under the influence of external or internal forces in the material at the weakened section arise elastic displacements and stresses that in some point in their energy reaches the value corresponding to the beginning of the phase transition. The transition is accompanied by a decrease in strength at this point and growth stresses in adjacent this region, the cross section of the processed material occurs a zone of weakening, propagating with the velocity of elastic waves in the metal. It is a transitional state of the metal, followed by loss of strength, determines the possibility of plastic deformation of the processed material without destruction.

In the external parts of the deformable metal and deforming tool, in relation to the field of softening, is the relaxation of elastic stresses with corresponding changes in the dimensions of the region of the softening and emitting in the area of heat deformation. Due to the large thermal conductivity of the zone of weakening the heat quickly dissipated outside. When this is done the reverse phase transition and recrystallization with education in the area softening of new crystallites, which significantly strengthened compared to the baseline due to the increase in surface and alloying of the remnants of the high energy phase. This single act of plastic deformation stops. Then again elastic deformation of the metal with the formation of a similar zone of weakening in any other the most prepared for this section, but with some increase in effort deformation.

\section{Research methods}

The above described mechanism of plasticity allows us to conclude that the linear size of a single zone softening and recrystallization $\Delta \mathrm{l}_{\mathrm{a}}$ for one act of plastic deformation is the sum of the elastic 
displacement in the direction of action of force of the external zones of the processed material $\Delta \mathrm{l}_{\mathrm{o}}$, elastic deformation of the tool and parts deforming machine $\Delta \mathrm{l}_{\mathrm{M}}$, as well as the working movement of the tool during the existence of the zone of softening $\Delta \mathrm{l}_{\mathrm{I}}$.

$$
\Delta \mathrm{l}_{\mathrm{a}}=\Delta \mathrm{l}_{\mathrm{o}}+\Delta \mathrm{l}_{\mathrm{M}}+\Delta \mathrm{l}_{\mathrm{I}}
$$

When laboratory testing, when the rigidity of the deforming device and tool much more stiffness of the sample and at low strain rates the main value that determines the total value of $\Delta \mathrm{l}_{\mathrm{a}}$, is the elastic deformation of the parts of a deformable material outside the zone of plasticity $\Delta \mathrm{l}_{\mathrm{o}}$. This value is determined by the elastic modulus of the sample material and yield strength. For most metals, it is approximately equal $l_{0} \cdot 10-3$.

Based on the analysis of the above expression (1) we can draw several conclusions about the possibility of controlling the properties of deformable material by changing the total stiffness of the system $\Delta \mathrm{l}_{\mathrm{a}}$ - deformable metal $\Delta \mathrm{l}_{\mathrm{o}}$ - deformable machine and tool $\Delta \mathrm{l}_{\mathrm{M}}$ - tool movement during the existence of the zone of weakening. Value $\Delta \mathrm{l}_{\mathrm{o}}$ depends on the size of the sample, its elastic and plastic properties, processing temperature. In specific conditions of production are minimal changes of this parameter.

In real industrial mechanisms, which in the development of technology makes maximum use of their strength parameters, the elastic deformation of the parts of the mechanism and the deforming tool can be comparable in magnitude with $\Delta \mathrm{l}_{\mathrm{o}}$ and even greatly exceed this value. In order to reduce the influence of elastic deformation of the machine and tool designers usually follow the path of increasing the rigidity of equipment that conducts to growth of the cross section and mass of the equipment. It should be emphasized that the main task of measures on strengthening deforming machines and tools is to improve the dimensional accuracy of the finished product, with changes in the structure and properties of deformable metal is not considered.

According to expression (1), when the absolute rigidity of the deforming parts of the machine and the deforming tool $\Delta \mathrm{l}_{\mathrm{M}}=0$, and then

$$
\Delta \mathrm{l}_{\mathrm{a}}=\Delta \mathrm{l}_{\mathrm{o}}+\Delta \mathrm{l}_{\mathrm{I}}
$$

Value $\Delta \mathrm{l}_{\mathrm{a}}$ corresponds to the crystallite size after recrystallization in a direction perpendicular to the deforming action efforts. Elementary calculations show that when applied velocities of the tool impact parameter $\Delta \mathrm{l}_{\mathrm{I}}$ on the value $\Delta \mathrm{l}_{\mathrm{a}}$ small. On this basis, the minimum size of a crystallite in the direction perpendicular to the deforming action efforts with absolute rigidity deforming machine and tool after plastic deformation will be determined mainly by the elastic properties of a deformable material.

Therefore, the change in the stiffness of the system of deformable metal - deforming tool deforming machine, you can control the size of the crystallites of a deformable material. As described above, reducing the strain in a single act (1) is usually done by increasing the stiffness. However, a similar result can come the opposite way - greatly reducing the stiffness of the system by introducing between the tool and deforming machine laying very low stiffness or a change in the design of the tool.

This pad is a kind of damper between the deformable material and deforming machine. The rate of passage through it of the relaxation elastic waves, resulting from a weakening in a single zone of deformation in the deformable metal, much less than that of the material of the tool or deforming machine. Consequently, during the existence of the zone of weakening wave stress relaxation machine making the move $\Delta \mathrm{l}_{\mathrm{M}}$, and the tool movement mechanism deforming machine $\Delta \mathrm{l}_{\mathrm{I}}$ not have time to be realized, and in this case $\Delta \mathrm{l}_{\mathrm{a}}=\Delta \mathrm{l}_{\mathrm{o}}$. That is, the introduction into the system of deformable material - deforming tool - deforming machine damper with infinitesimal rigidity 
produces effects on deformable material similar to the construction of the machine and the tool with infinite stiffness.

The experiments conducted on the upsetting, tension and rolling [6,7] showed that the change in the stiffness of the deforming tool or deforming machine (press, bursting machines, rolling mill and so on) always leads to a change in material properties of the deformable billet, which is manifested in its plasticity and energy-power parameters of deformation and structure.

On machine-building and metallurgical plants the deforming equipment periodically subjected to modernization, which in many cases is associated with the change in the stiffness of deforming machines. In the metallurgical industry modernization of rolling mills is carried out by replacing a bases, loaded devices, bearings of the rolls, the introduction of various devices of the bending rolls, etc.

All these design changes alter the stiffness characteristics of rolling mill. But it is considered that any changes in the structure and properties of the processed metal does not occur. As a result of such established opinion of special research in this direction was not carried out and about the actual change properties of laminated metal can be judged not by direct studies of the structure, but only for the data changes its mechanical characteristics.

\section{Results and discussion}

A typical example of such changes in the properties of rolled metal due to reconstruction are the statistics obtained from the results of measurement of the strength characteristics of steel, laminated on the hot rolling mill 1700 of Karaganda metallurgical combine (now JSC "ArcelorMittal Temirtau") in 1998 and in 2002

In 1999 it was done reconstruction of rolling mill with four last finishing stands hydraulic screwdown devices (stands 9-12). Push mechanisms are designed to control the gap between the work rolls in the stands of the rolling mill with the aim of obtaining the finished product with minimum deviations in thickness. Since when rolling long size billets properties of the metal along the length change in one direction or another, then one of the tasks of these devices is the regulation of the gap between the rolls in order to reduce the longitudinal thickness variation of the metal, which is produced by the signal from the thickness gauge.

Usual design of the pushing device consists of a rotating propeller with an electric drive. At high speed rolling, due to the inertia of the actuator, a mechanical pressure device work with a significant delay. The main problem solved by the substitution of mechanical devices for hydraulic, is a manifold increase in response speed and getting the metal with the lower longitudinal strip thickness variation.

However, the installation of the hydraulic pushing devices on four of the 12 stands of rolling mill has led to a reduction in the stiffness of the stands and to statistically significant changes in the mechanical properties of rolled metal. Was the analysis of properties of two low carbon steels. AISI 1008 and its analog steel USPHT-1, which are mild and do not undergo hardening. The chemical composition of the steels shown in table 1 . All surveyed more than 10,000 meltings.

Table 1 - Chemical composition of low carbon steels

\begin{tabular}{|c|c|c|c|c|c|c|c|c|c|}
\hline \multicolumn{10}{|c|}{ Content of elements, \% } \\
\hline $\mathrm{C}$ & $\mathrm{Si}$ & $\mathrm{Mn}$ & $\mathrm{Cu}$ & $\mathrm{Cr}$ & $\mathrm{Ni}$ & $\mathrm{P}$ & $\mathrm{S}$ & As & $\mathrm{N}$ \\
\hline \multicolumn{10}{|c|}{ AISI 1008} \\
\hline $\begin{array}{l}0,05- \\
0,12\end{array}$ & $\begin{array}{l}\text { till } \\
0,03 \\
\end{array}$ & $\begin{array}{l}0,25- \\
0,5\end{array}$ & till 0,3 & till 0,1 & till 0,3 & $\begin{array}{l}\text { till } \\
0,035\end{array}$ & till 0,4 & $\begin{array}{l}\text { till } \\
0,08\end{array}$ & - \\
\hline $\mathrm{C}$ & Si & $\mathrm{Mn}$ & $\mathrm{Cu}$ & $\mathrm{Cr}$ & $\mathrm{Ni}$ & $\mathrm{P}$ & $\mathrm{S}$ & $\mathrm{Al}$ & $\mathrm{N}$ \\
\hline \multicolumn{10}{|c|}{ USPHT-1 } \\
\hline $\begin{array}{l}0,11- \\
0,18\end{array}$ & $<0,05$ & $\begin{array}{l}0,3- \\
0,45\end{array}$ & $<0,3$ & $<0,3$ & $<0.3$ & 0,03 & 0,025 & $\begin{array}{l}0,02- \\
0,07\end{array}$ & $\begin{array}{l}0,02- \\
0,07\end{array}$ \\
\hline
\end{tabular}


The results of the comparative analysis of the mechanical properties of steels, laminated in 19982002 on hot rolling mill 1700 of Karaganda metallurgical combine before reconstruction and after installation of the hydraulic screw-down devices for steels AISI 1008 and USPHT-1 are presented in tables 2-3.

Table 2 - Results of analysis of mechanical properties of steel AISI 1008

\begin{tabular}{|c|c|c|c|c|c|}
\hline \multirow[t]{3}{*}{ Thickness, mm } & \multicolumn{5}{|c|}{ Tensile strength, MPa } \\
\hline & \multicolumn{2}{|c|}{ Before reconstruction } & \multicolumn{2}{|c|}{ After reconstruction } & \multirow{2}{*}{$\begin{array}{c}\text { Change, } \\
\%\end{array}$} \\
\hline & $-\quad+$ & $\mathrm{X}_{\mathrm{AV}}$ & $-\quad+$ & $\mathrm{X}_{\mathrm{AV}}$ & \\
\hline$\leq 2,0$ & $330-455$ & 376,7 & $355-455$ & 385,3 & $+2,3$ \\
\hline $2,0-3,0$ & $250-485$ & 360,7 & $335-445$ & 383,8 & $+6,4$ \\
\hline 4,0 & $315-430$ & 358,2 & $360-390$ & 377 & $+5,2$ \\
\hline $6-8$ & $320-380$ & 344,3 & $325-370$ & 349 & $+1,4$ \\
\hline Св. 8 & $320-390$ & 337,1 & $310-375$ & 342,9 & $+1,7$ \\
\hline \multirow[t]{3}{*}{ Thickness, mm } & \multicolumn{5}{|c|}{ Yield strength, MPa } \\
\hline & \multicolumn{2}{|c|}{ Before reconstruction } & \multicolumn{2}{|c|}{ After reconstruction } & \multirow{2}{*}{$\begin{array}{c}\text { Change, } \\
\%\end{array}$} \\
\hline & $-\quad+$ & $\mathrm{X}_{\mathrm{AV}}$ & $-\quad+$ & $\mathrm{X}_{\mathrm{AV}}$ & \\
\hline$\leq 2,0$ & $255-360$ & 311,8 & $235-370$ & 318,4 & $+2,1$ \\
\hline $2,0-3,0$ & $230-355$ & 292,1 & $230-350$ & 300,8 & $+3,0$ \\
\hline 4,0 & 205-315 & 266,0 & 265-315 & 296,1 & $+11,3$ \\
\hline $6-8$ & $195-315$ & 235,3 & $215-275$ & 238,9 & $+1,5$ \\
\hline Св. 8 & $185-320$ & 223,3 & $195-340$ & 228,4 & $+2,3$ \\
\hline \multirow[t]{3}{*}{ Thickness, mm } & \multicolumn{5}{|c|}{ Elongation, \% } \\
\hline & \multicolumn{2}{|c|}{ Before reconstruction } & \multicolumn{2}{|c|}{ After reconstruction } & \multirow{2}{*}{$\begin{array}{c}\text { Change, } \\
\%\end{array}$} \\
\hline & $-\quad+$ & $\mathrm{X}_{\mathrm{AV}}$ & $-\quad+$ & $\mathrm{X}_{\mathrm{AV}}$ & \\
\hline$\leq 2,0$ & 26-39 & 33,49 & $26-41$ & 31,99 & $-4,5$ \\
\hline $2,0-3,0$ & $21-44$ & 35,35 & $21,5-40$ & 32,79 & $-7,2$ \\
\hline 4,0 & $32-49$ & 42,41 & $31-45$ & 38,1 & $-10,2$ \\
\hline $6-8$ & $31-45$ & 39,3 & $34-44$ & 39,3 & 0 \\
\hline Св. 8 & $33-47$ & 39,4 & $31-45$ & 38,91 & $-1,3$ \\
\hline
\end{tabular}

Table 3 - Results of analysis of mechanical properties of steel USPHT-1

\begin{tabular}{|c|c|c|c|c|c|}
\hline Thickness, mm & \multicolumn{5}{|c|}{ Tensile strength, MPa } \\
\cline { 2 - 5 } & Before reconstruction & After reconstruction & $\begin{array}{c}\text { Change, } \\
\%\end{array}$ \\
\cline { 2 - 5 } & -+ & $\mathrm{X}_{\mathrm{AV}}$ & -+ & $\mathrm{X}_{\mathrm{AV}}$ & \\
\hline$\leq 2,0$ & $325-415$ & 369,1 & $350-430$ & 380,4 & $+3,1$ \\
\hline $2,0-3,0$ & $330-480$ & 368,8 & $350-450$ & 384,8 & $+4,3$ \\
\hline $3-4$ & $330-430$ & 363,6 & $335-410$ & 372,8 & $+2,5$ \\
\hline $4-6$ & $320-445$ & 361,2 & $340-430$ & 367,5 & $+1,7$ \\
\hline $6-8$ & $315-395$ & 353,6 & $330-385$ & 359,8 & $+1,7$ \\
\hline Thickness, mm & \multicolumn{6}{|c|}{ Yield strength, MPa } \\
\hline
\end{tabular}




\begin{tabular}{|c|c|c|c|c|c|}
\hline & \multicolumn{2}{|c|}{ Before reconstruction } & \multicolumn{2}{|c|}{ After reconstruction } & \multirow{2}{*}{$\begin{array}{c}\text { Change, } \\
\%\end{array}$} \\
\hline & $-\quad+$ & $\mathrm{X}_{\mathrm{AV}}$ & $-\quad+$ & $\mathrm{X}_{\mathrm{AV}}$ & \\
\hline$\leq 2,0$ & $235-325$ & 284,2 & $255-335$ & 295,4 & $+3,9$ \\
\hline $2,0-3,0$ & $225-335$ & 271,0 & $235-355$ & 286,5 & $+5,7$ \\
\hline $3-4$ & $210-320$ & 253,6 & $235-315$ & 261,7 & $+3,2$ \\
\hline $4-6$ & $200-300$ & 246,6 & $220-300$ & 251,3 & $+1,9$ \\
\hline 6-8 & $195-310$ & 232,4 & $215-260$ & 236,6 & $+1,8$ \\
\hline \multirow[t]{3}{*}{ Thickness, mm } & \multicolumn{5}{|c|}{ Elongation, \% } \\
\hline & \multicolumn{2}{|c|}{ Before reconstruction } & \multicolumn{2}{|c|}{ After reconstruction } & \multirow{2}{*}{$\begin{array}{c}\text { Change, } \\
\%\end{array}$} \\
\hline & -+ & $\mathrm{X}_{\mathrm{AV}}$ & $-\quad+$ & $\mathrm{X}_{\mathrm{AV}}$ & \\
\hline$\leq 2,0$ & $36-49$ & 44,25 & $34-48$ & 40,91 & $-7,5$ \\
\hline $2,0-3,0$ & $33-53$ & 45,72 & $34-50$ & 43,62 & $-4,6$ \\
\hline $3-4$ & $32-55$ & 47,37 & $38-52$ & 45,15 & $-4,7$ \\
\hline 4-6 & $37-54$ & 48,34 & $39-53$ & 46,62 & $-3,6$ \\
\hline $6-8$ & $42-58$ & 50,3 & $45-52$ & 48,78 & $-3,0$ \\
\hline
\end{tabular}

\section{Conclusions}

In the tables is presented the analysis of results of studies of the properties of hot rolled steel statistically shows that are produced as a result of reconstruction of the change in the stiffness of the working stands rolling mill has led to an increase in the tensile strength and yield strength and lower limit plasticity laminated metal. Therefore, the change in the stiffness of deforming device and tool causes a change in the properties.

\section{References}

[1] Kravz-Tarnavsky B.P. Specific strip steel. Journal of Russian metallurgical society, 1928, №3. - p. 162.

[2] Bochvar A.A., Swiderskaya Z.A. Phenomenon of superplasticity in alloys of zinc and aluminum // Proceedings of the Academy of Sciences of the USSR, 1945, №9. p. 821-824.

[3] Presnyakov A.A. Localization of plastic deformation. - Alma-Ata: Nauka, 1981. - 120 p.

[4] Panin, V.E., Egorushkin V.E., Panin A.V., Moiseenko D.D. Nature of localization of plastic deformation of solids // Journal of technical physics, 2007, vol.77, №.8.- p. 62-69.

[5] Kenzhaliev B.K., Kurapov G.G., Mofa N.N., Degtyareva A.S., Chernoglazova T.V., Mamytov B.T., Suleymenov E.N. The concept of physical-chemical nature of plastic deformation // Creation of scientific basis of fundamentally new chemical and metallurgical technologies, adapted to the resource base in Kazakhstan. Almaty, 2003. - p. 341-347.

[6] Localization of plastic deformation and nonequilibrium structural deformation transformation. Selected works. Authors-compilers: Kenzhaliev B.K., Kurapov G.G., Mofa N.N., Degtyareva A.S., Chernoglazova T.V., Suleymenov E.N. / Almaty: Publishing House "Complex", 2004 $271 \mathrm{p}$.

[7] Kurapov G.G., Naizabekov A.B., Lezhnev S. ., Zhanserkeeva Z.A., Panichkin A.V. Plastic deformation of metals as a physical-chemical process. Educational textbook. Temirtau: KSIU, 2011.-78 p. 